\title{
The ghost of mimicry past: laboratory reconstitution of an extinct butterfly 'race'
}

\author{
MAURICIO LINARES* \\ Instituto de Genética, Universidad de los Andes, Calle 18 Carrera 1E, Santafé de Bogotá, Colombia
}

\begin{abstract}
Four variable traits that determine mimetic colour patterns in the butterfly, Heliconius cydno, evolved between 1908 and 1984-91. There was a decline in the frequencies of alleles and phenotypes that confer resemblance to the co-mimic, Elzunia humboldt regalis, and an increase in the frequencies of alleles and phenotypes that confer resemblance to the alternative co-mimic, Heliconius erato chestertonii. Elzunia humbolt regalis was formerly common but is now restricted to forest fragments, whereas $H$. e. chestertonii occurs principally in disturbed habitats, where it is now common. Human disturbance of habitats is thought to have changed the relative abundances of the two co-mimics, and hence the selection operating on $H$. cydno. The form of $H$. cydno that is presumed to have been a near-perfect mimic of $H$. $h$. regalis is no longer found in the wild: this form would have been homozygous for the rarer alleles at all four loci. It has been possible to reconstruct this form on two occasions in the laboratory, breeding from partially heterozygous wild-caught female butterflies.
\end{abstract}

Keywords: butterfly mimicry, Heliconius microevolution, mimicry evolution, Müllerian mimicry, population genetics, rapid microevolution.

\section{Introduction}

It has previously been reported that changes in plant communities brought about by man have resulted in rapid evolution of insects that depend on these plants for camouflage (Kettlewell, 1973; Lees, 1981; Endler, 1986) or food (Gould, 1979; Tabashnik, 1983; Thomas et al., 1987; Feder et al., 1988; Singer et al., 1993). This report, for the first time, presents strong evidence indicating that mimetic relationships can evolve in response to human-mediated disruption of natural habitats. Furthermore, in Heliconius butterflies there has been a great deal of reporting of the outcome of evolutionary change and a great deal of theorizing about how it might occur, but very little documentation of it actually happening, as this publication attempts to do. Of particular interest is a possible relatively recent evolutionary change in Heliconius hermathena (Brown \& Benson, 1977). However, unlike this paper, Brown \& Benson did not document the actual change over time and did not suggest a possible relationship between a man-made effect on selective pressures associated with mimicry and the evolutionary change itself.

*E-mail: mlinares@uniandes.edu.co
Members of the butterfly genus Heliconius and of the subfamily Ithomiinae are unpalatable (Brower $e t$ al., 1963; Chai, 1986) and important components of Müllerian mimicry systems throughout the neotropics (Brown, 1979, 1981; Turner, 1988; Gilbert, 1991; Mallet, 1993; Brower, 1994a,b). In Müllerian mimicry, two or more unpalatable species converge on one colour pattern that is recognized and avoided by potential predators. The species involved in a Müllerian mimetic association are thought to enjoy benefits through: (1) sharing the cost of teaching their distastefulness to potential predators; and (2) advertising their toxicity more effectively by increasing the overall density of butterflies that transmit the same warning signal.

Heliconius species are usually monotypic in a given locality. However, in the southern part of the Cauca Valley (Andes, Colombia), the mimetic butterfly, Heliconius cydno, possesses two major forms, gustavi and weymeri, which co-occur in several localities as polymorphic phenotypes of single interbreeding populations (Linares, 1996). These forms differ in that $H$. cydno f. gustavi has a black forewing, whereas $H$. cydno f. weymeri has two white bands in the medial area of the forewing (Fig. 1). Laboratory crosses show that the difference between these forms is controlled by a single autosomal Mendelian gene with black forewing, controlled by 
allele $L^{G}$, being nearly dominant over white-banded forewing, controlled by allele $L^{C}$ (Linares, 1996). These results are consistent with previous genetic studies involving other Heliconius (Sheppard et al., 1985; Mallet, 1986, 1989; Turner, 1971a,b, 1981, 1987).

Heliconius cydno f. gustavi and $H$. erato chestertonii are strikingly similar (Fig. 1), sympatric co-mimics (Eltringham, 1916). The likely co-mimic of $H$. cydno f. weymeri is the ithomiine butterfly, Elzunia humboldt regalis (Fig. 1), which shares with weymeri the shape, colour and position of a yellow band in the hindwing and the presence of two areas of white coloration in the forewing, all superimposed on a black background. In spite of the fact that most weymeri lack some traits present in $E$. $h$. regalis (see below), there is presently no other lepidopteran species in the southern part of the Cauca Valley that could be a co-mimic of $H$. cydno f. weymeri.

\section{Materials and methods}

Between 1984 and 1991, specimens of Heliconius cydno and Heliconius erato were collected from the Río Aguacatal region near the village of El Saladito located $18 \mathrm{~km}$ north-west of Cali (Colombia). During this period, no individuals of $E$. $h$. regalis were observed in this particular area. The individuals of $H$. cydno from these samples and others, almost certainly gathered by European collectors in the Río Aguacatal region before 1910, were assigned to a given genotype based on criteria established by previous genetic studies (Linares, 1996). The genotypic and allelic frequencies at five wing pattern loci were estimated and compared between samples from different periods.

The sample from 1908 is composed of specimens labelled as collected by A. H. Fassl in three localities within a circle of approximately $5 \mathrm{~km}$ in radius: Villa Elvira, Río Aguacatal and Tocotá. My sample is composed of specimens collected in the Río Aguacatal region during 1984, 1985, 1987, 1989, 1990 and 1991.

Genetic experiments were performed in La Vega (Colombia), a village $50 \mathrm{~km}$ north-west of Santafé de Bogotá, and in greenhouse insectaries atop Patterson Laboratory, University of Texas, Austin, U.S.A. The two mated wild-caught females mentioned here (caught at Río Aguacatal) were kept in isolation laying eggs. Desired broods were obtained by isolating the two potential parents in an insectary cage. The putative genotypes of the family members were inferred through visual examination with a stereoscope and analysis of the segregation patterns obtained in particular broods mentioned here and elsewhere (Linares, 1996). Chi-square was used for contingency table analysis and goodness of fit. Heterogeneity between the distribution of genotypes by sexes for a single locus was tested with a Monte Carlo simulation 20,000 times (Lewontin \& Felsenstein, 1965). Unless stated otherwise, the reader can assume that the sexes are homogeneous.

Passiflora edulis, P. biflora and P. caerulea (Passifloraceae) were used for egg laying and mass rearing of broods. Eggs were collected daily in Austin and every 3 days in La Vega. Larvae were reared in groups of about 10 individuals in separate containers with abundant food. Psiguria spp. (Cucurbitaceae) and Lantana spp. (Verbenaceae) flowers were provided as nectar and pollen sources for adults. Further details of insectary maintenance are given by Turner (1974).

\section{Results and discussion}

H. cydno and its putative co-mimics are sympatric in several localities in the southern part of the Cauca Valley in the Andes of Colombia (Brown, 1979; Linares, 1989; Torres \& Takahashi, 1983). However, the two presumed co-mimics of $H$. cydno are denizens of very different habitats. Heliconius erato chestertonii lives along forest edges and in disturbed areas (Mallet, 1984), whereas $E$. $h$. regalis is characteristic of undisturbed deeply shaded forest. We expect the relative abundance of these co-mimics to change in response to human disturbance of the habitat. Road building between Cali and Buenaventura, with associated human population increases, started in 1600 (Ramos, 1971), increased rapidly around 1860 (Anon, 1981) and increased again between 1926 and 1945. As expected, E. h. regalis is now rare and occurs at four heavily shaded locations in the least disturbed remaining forest habitats, whereas $H$. e. chestertonii has increased (Table 1).

These recent changes in abundance of the co-mimics of $H$. cydno should have altered targets of selection on wing pattern, with present selection acting against polymorphic forms that resemble $E$. $h$. regalis and in favour of those that resemble $H$. $e$. chestertonii. This hypothesis predicts that $H$. cydno f. weymeri should be decreasing, whereas gustavi should be increasing. In fact, $H$. cydno f. weymeri has declined from an estimated frequency of 0.74 before 1896 (Staudinger, 1896) to 0.49 in Fassl's collection of 1908 and again to 0.33 in 1984-91 (Table 1). Correspondingly, gustavi has increased from 0.26 before 1896 to 0.67 at present. The procedure of comparing population samples by different workers 


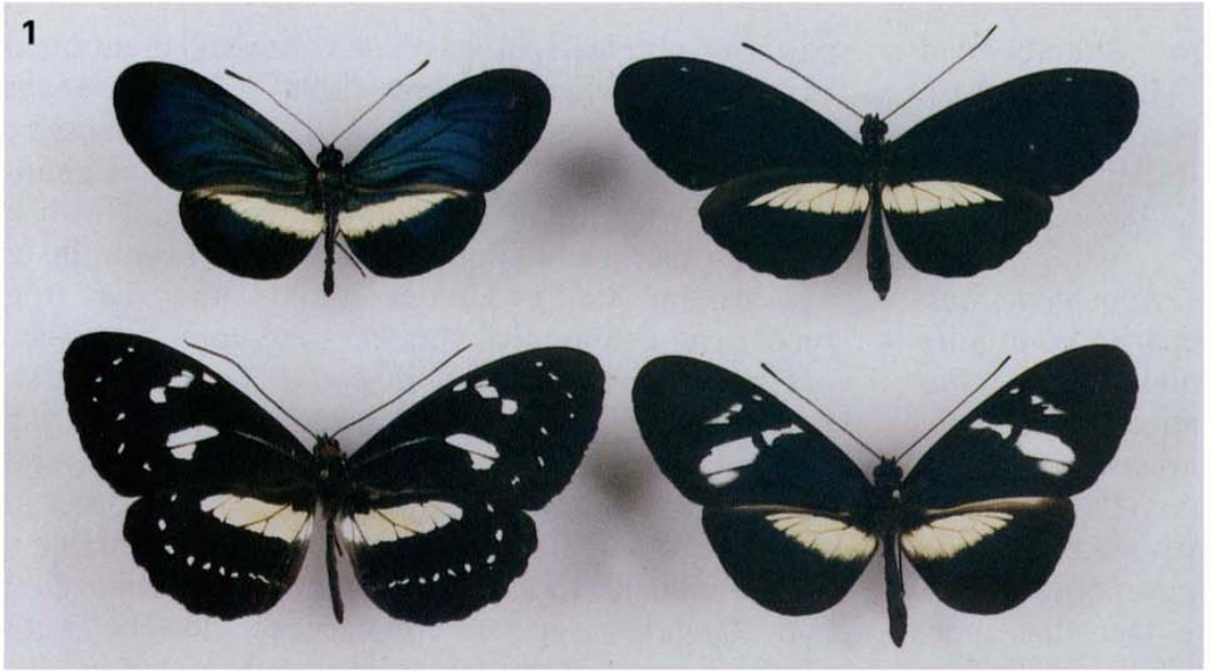

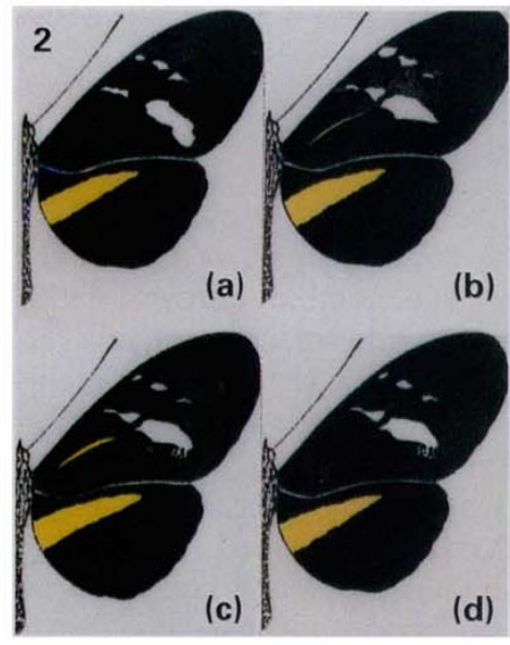

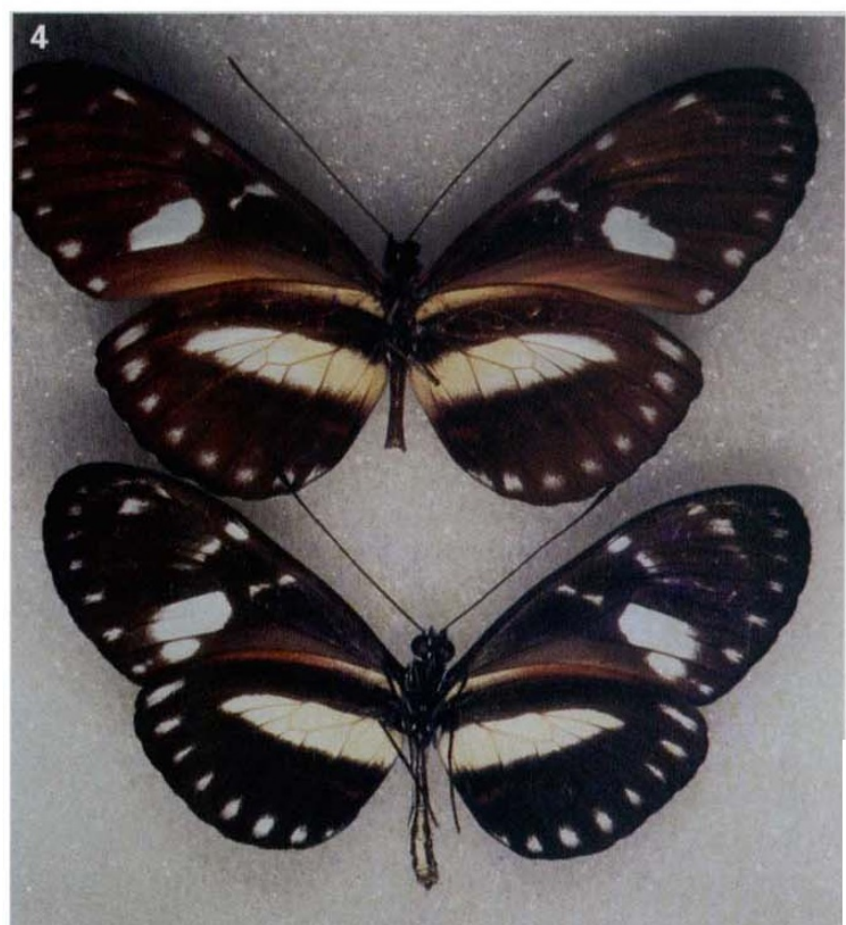

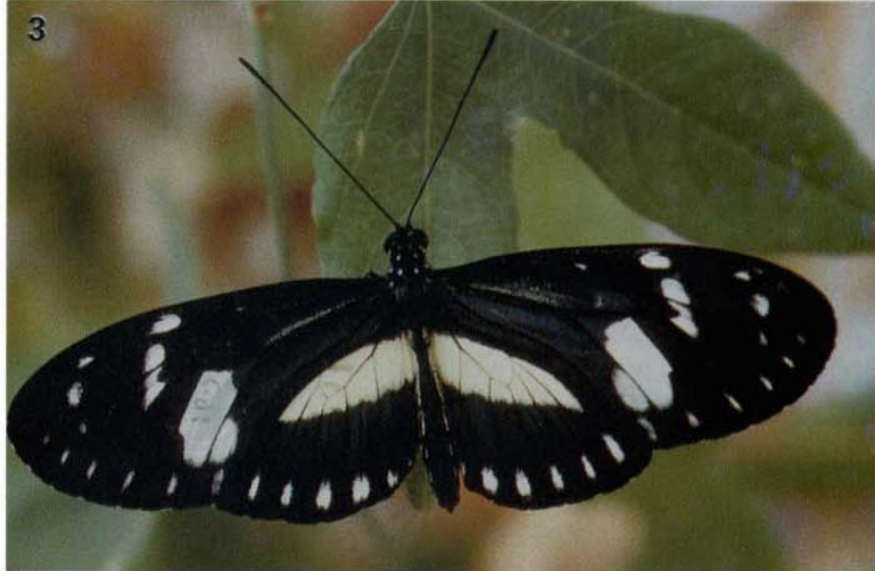

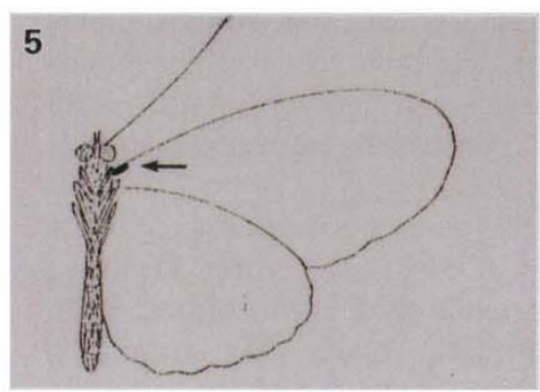

(c) The Genetical Society of Great Britain, Heredity, 78, 628-635. 
Table 1 Changes over time in abundance of major forms of Heliconius cydno (males/females) and co-mimics at the Río Aguacatal region

\begin{tabular}{llccccc}
\hline Date & Collector & Elzunia & $\begin{array}{c}\text { H. erato } \\
\text { chestertonii }\end{array}$ & $\begin{array}{c}\text { H. cydno } \\
\text { gustavi }\end{array}$ & $\begin{array}{c}\text { H. cydno } \\
\text { weymeri }\end{array}$ & $\begin{array}{c}\text { Frequency } \\
\text { of weymeri }\end{array}$ \\
\hline$<1896$ & Unknown & Unknown & Unknown & $3 / 2$ & $7 / 7$ & 0.7368 \\
1908 & Fassl & 6 & Some & $26 / 19$ & $30 / 14$ & 0.4943 \\
$1984-91$ & Linares & 0 & $>200$ & $120 / 23$ & $52 / 17$ & 0.3254 \\
\hline
\end{tabular}

The $19 \mathrm{H}$. cydno specimens of the first row are reported by Staudinger (1896), but the collector and the precise date of collection is not mentioned. The $89 \mathrm{H}$. cydno and six Elzunia specimens reported as collected by Fassl are found in seven natural history museums (a list of which can be obtained from the author). It was assumed that all the specimens found labelled as collected by Fassl in the Río Aguacatal region were actually collected by him in 1908. This is a reasonable assumption given that he spent nearly a year collecting butterflies in this particular region in 1908 and that he was regarded as one of the bestqualified and most talented collectors from Europe who worked in the neotropics at that time. Although I have not seen any specimens of $H$. $e$. chestertonii that are labelled as collected by Fassl, in one of his publications (1914) he mentions that he captured some, along with the forms weymeri and gustavi of $H$. cydno, in the Río Aguacatal region. The relative frequency of the major forms of $H$. cydno is not heterogeneous between the sample reported by Staudinger and that of Fassl $(2 \times 2$ contingency table analysis, d.f. $=1$, $P=0.054)$ but it is between the samples of Fassl and Linares $(2 \times 2$ contingency table analysis, d.f. $=1, P=0.0057$ ).

over 75-80 years is a potential problem. It was not possible to ascertain whether Fassl sampled specimens randomly but, as Staudinger (1896) had previously described gustavi as an aberrant of weymeri, if there were any bias it would have been likely to have been in favour of collecting more specimens of gustavi. This bias would result in an underestimate of the reduction in frequency of the weymeri form between 1908 and 1984-91. As samples were taken randomly among those insects seen flying, they could be biased only by differential flight behaviour of the two forms.

At the genotypic level, the allele $\left(L^{C}\right)$ that controls the presence of the weymeri phenotype has appar- ently declined significantly between 1908 and 1984-91 only among the male population (Table 2). At this locus, the distribution of genotypes by sexes is heterogeneous in the 1984-91 sample (Monte Carlo simulation, $2 \times 3$ table, $P=0.0174 \pm 0.0009$ ). The frequencies of alleles $L^{G}$ and $L^{C}$ (and the corresponding genotypic frequencies) are heterogeneous between males (but not between females) sampled in 1908 and 1984-91 (for genotypic frequencies: $2 \times 3$ contingency table analysis, d.f. $=3$, $P=0.006$, Table 2 ; for allelic frequencies: $2 \times 2$ contingency table analysis, d.f. $=1, P=0.0179$ ). Thus, the estimated allele frequency change for the $L^{C}$ allele between 1908 and $1984-91$ is -12.4 per

Fig. 1 Mimetic relationships between major forms of Heliconius cydno and their respective co-mimics. Top row: Heliconius erato chestertonii (left) and Heliconius cydno f. gustavi (right). Bottom row: Elzunia humboldt regalis (left) and Heliconius cydno f. weymeri (right).

Fig. 2 Presence (a) and absence (b) of white oval in the medial area of the forewing and presence (c) and absence (d) of yellow line trait along the vein that defines the forewing discal cell, both components of $H$. cydno colour pattern.

Fig. 3 Laboratory-produced specimen of Heliconius cydno whose colour pattern mimics very closely the colour pattern of the toxic ithomiine butterfly, Elzunia humboldt regalis. The individual whose forewing underside is labelled C-91 is supposed to be homozygous at four Mendelian loci (putative genotype $L^{C} L^{C} S_{2} S_{2} b_{2} \mathrm{Wo}_{2} \mathrm{Wo}_{2} \mathrm{Yl}_{2} \mathrm{Yl}_{2}$ ) controlling major resemblance with the latter.

Fig. 4 Ventral view of one of the type-specimens of Heliconius weymeri submarginatus (currently Heliconius cydno weymeri f. weymeri with full expression of submarginatus) collected by Fassl, from the British Museum of Natural History (top) and $H$. cydno laboratory-reconstituted mimic of $E$. h. regalis (bottom).

Fig. 5 Drawing of the presence of the red-brown dot (represented by a black dot) located in the basal area of the forewing costal vein (underside only) of H. cydno.

(C) The Genetical Society of Great Britain, Heredity, 78, 628-635. 
Table 2 Genotype distributions of Heliconius cydno wing pattern loci in 1908 and 1984-91 at Río Aguacatal region

\begin{tabular}{|c|c|c|c|c|c|}
\hline \multirow[b]{2}{*}{ Gene } & \multirow[b]{2}{*}{ Genotype (phenotype) } & \multicolumn{2}{|c|}{ Year } & \multirow[b]{2}{*}{$\begin{array}{l}\text { Allele } \\
\text { frequency } \\
\text { decrease }\end{array}$} & \multirow[b]{2}{*}{$\begin{array}{c}\text { Chi-square } \\
\text { probability, } 2 \times 3 \\
\text { contingency table }\end{array}$} \\
\hline & & $\begin{array}{r}1908 \\
(\mathrm{~m}\end{array}$ & $\begin{array}{l}\text { 1984-91 } \\
\text { nales) }\end{array}$ & & \\
\hline 1 & $\begin{array}{l}L^{G} L^{G}(\text { gustavi }) \\
L^{G} L^{C} \text { (gustavi) } \\
L^{C} L^{C} \text { (weymeri) }\end{array}$ & $\begin{array}{c}5 / 8 \\
21 / 11 \\
30 / 14\end{array}$ & $\begin{array}{c}18 / 9 \\
102 / 14 \\
52 / 17\end{array}$ & $-12.4 \%\left(L^{C}\right)$ & $P=0.006$ \\
\hline 2 & $\begin{array}{l}S b_{1} S b_{1} \text { (no subm.) } \\
S b_{1} S b_{2} \text { (subm. interm.) } \\
S b_{2} S b_{2} \text { (submarginatus) }\end{array}$ & $\begin{array}{c}27 / 18 \\
27 / 13 \\
2 / 2\end{array}$ & $\begin{array}{c}113 / 26 \\
59 / 14 \\
0 / 0\end{array}$ & $-9.7 \%\left(S b_{2}\right)$ & $P=0.0011$ \\
\hline 3 & $\begin{array}{l}W o_{1} W o_{1} \text { (no white oval) } \\
W_{1} W o_{2} \text { (w. o. interm.) } \\
W_{2} W o_{2} \text { (white oval) }\end{array}$ & $\begin{array}{l}24 / 29 \\
25 / 0 \\
7 / 4\end{array}$ & $\begin{array}{c}107 / 35 \\
64 / 3 \\
1 / 2\end{array}$ & $-15.6 \%\left(W_{2}\right)$ & $P=0.0001$ \\
\hline 4 & $\begin{array}{l}Y_{l} Y l_{l} \text { (no yellow line) } \\
Y l_{I} Y l_{2} \text { (yellow line interm.) } \\
Y l_{2} Y l_{2} \text { (yellow line) }\end{array}$ & $\begin{array}{c}26 / 17 \\
23 / 15 \\
7 / 1\end{array}$ & $\begin{array}{c}118 / 20 \\
51 / 19 \\
3 / 1\end{array}$ & $-11.9 \%\left(Y l_{2}\right)$ & $P=0.0019$ \\
\hline 5 & $\begin{array}{l}G_{l} G_{l} \text { (no red dot) } \\
G_{l} G_{2} \text { (red dot interm.) } \\
G_{2} G_{2}(\text { red dot) }\end{array}$ & $\begin{array}{l}19 / 17 \\
19 / 10 \\
18 / 6\end{array}$ & $\begin{array}{l}64 / 14 \\
79 / 19 \\
29 / 7\end{array}$ & $-3.2 \%\left(G_{2}\right)$ & $P=0.0468$ \\
\hline
\end{tabular}

Estimates of allele frequency change for $L^{G} / L^{C}$ and $W_{1} / W o_{2}$ are based only on males: the distribution of genotypes by sexes is heterogeneous and the females do not show a significant change between 1908 and 1984-91 at these two loci. The distribution of genotypes does not show statistically significant deviations with respect to Hardy-Weinberg expectations, except: $L^{G} / L^{C}$ locus, 1984-91 males; $S b_{I} / S b_{2}$ locus, 1984-91 males; $W o_{1} / W_{o_{2}}$ locus, 1908 females and both $1984-91$ males and females; $G_{l} / G_{2}$ locus 1908 males (chi-squared analysis, d.f. $=1, P<0.05$ in all seven cases; sexes were analysed separately).

cent among males and 0.9 per cent among females. The lack of a significant difference between the estimates obtained from the females is very likely the result of the small number of individuals of this sex (compared with males), especially in the 1984-91 sample (40 females vs. 172 males; see Table 2). The fact that the distribution of genotypes by sexes at the $L^{G} / L^{C}$ locus is heterogeneous in the 1984-91 sample could be a consequence of a difficulty in the classification of the heterozygotes associated with an effect of sex on dominance of $L^{G}$ over $L^{C}$ and/or a sample bias or a random effect. Linares (1996) has presented some evidence that may indicate that the sex of the individual can affect dominance through the appearance of melanic scales at the white oval ( $\mathrm{Wo}_{\mathrm{I}} / \mathrm{Wo}_{2}$ locus; Fig. 2), which appears in the medial area of the forewing between the cubital 2 and the second anal veins, adjacent to the region (between cubital veins 1 and 2) where the appearance of some white scales is taken as an indicator of a putative $L^{G} L^{C}$ heterozygote.

An additional trait, submarginatus (Fassl, 1912), which is controlled by allele $S b_{2}$ from a second locus (Linares, 1996), can appear in either form of $H$. cydno. It is distinguished by a series of seven to eight white submarginal dots in both the hind and forewing, plus a very small, but conspicuous, white band in the postmedial area of the forewing (Figs 3 and 4). In weymeri, submarginatus improves the similarity to $E$. $h$. regalis (compare Fig. 1 and Fig. 3), but in gustavi it detracts from the mimicry of $H$. e. chestertonii. Table 2 shows a significant decrease in the frequency of the allele that controls submarginatus between 1908 and the present. In combination with the increase in frequency of gustavi that has also occurred over the same timespan, we see an increase in the polymorphic form whose model has become abundant ( $H$. cydno f. gustavi non-submarginatus) and a decrease in the form whose model has become rare (H. cydno f. weymeri submarginatus).

The submarginatus trait is partly expressed in the heterozygous condition (see below), but the homozygote $\left(\mathrm{Sb}_{2} \mathrm{Sb}_{2}\right)$ is a better mimic of $E$. $h$. regalis (compare Fig. 1 and Fig. 3). Two of Fassl's $26 \mathrm{H}$. cydno f. weymeri submarginatus (one of them is shown in Fig. 4) were homozygous, whereas all 22 recently sampled $H$. cydno f. weymeri submarginatus were heterozygotes $\left(S b_{1} S b_{2}\right)$. Thus, the best mimic of 
$E$. h. regalis, homozygous $H$. cydno f. weymeri submarginatus (genotype $L^{C} L^{C} S b_{2} S b_{2}$ ), has declined to the point where it is not present in the sample of 212 insects from Río Aguacatal that were compared with Fassl's 1908 sample from the same location. The presumed original mimic of $E$. $h$. regalis is either extinct, or almost so, in the region from which it was originally sampled.

The submarginatus trait improves the mimicry between $H$. cydno f. weymeri and $E$. $h$. regalis but does not render it perfect. There are still two traits present in $E$. $h$. regalis that are absent from $H$. cydno f. weymeri submarginatus, as described. These are: (1) a yellow line along the vein that defines the discal cell of the forewing; (2) a small white oval (mentioned before) in the medial area of the forewing (Fig. 2). These two traits are all inherited in a simple Mendelian manner (Linares, 1996): the presence of the first is controlled by allele $Y_{2}$ and the presence of the second by allele $\mathrm{Wo}_{2}$ (from two additional loci). They are expressed more fully in form weymeri than in gustavi. Thus, their expression is stronger in the form in which they contribute to mimicry. Like the submarginatus trait, these two traits still exist in natural populations at low frequency and the alleles that control them show statistically significant declines between 1908 and 1984-91 (Table 2).

In both the 1908 and the 1984-91 samples, the distribution of genotypes by sexes at the $\mathrm{Wo}_{1} / \mathrm{Wo}_{2}$ locus is heterogeneous (for the 1908 sample, Monte Carlo simulation, $2 \times 3$ table, $P=0$, and for the 1984-91 sample, Monte Carlo simulation, $2 \times 3$ table, $P=0.0001 \pm 0.00008)$. In both samples, there appears to be a deficiency of heterozygous females with respect to Hardy-Weinberg expectations (Table 2). Although this observation is puzzling, it is likely that the deficiency of $\mathrm{Wo}_{1} \mathrm{Wo}_{2}$ females is the result of a possible effect of sex (Linares, 1996; see above) on the expression of the $\mathrm{Wo}_{1} / \mathrm{Wo}_{2}$ locus and/or a sample bias owing to the relatively small number of females in the two samples.

Because these two traits still exist, polymorphic populations of $H$. cydno from the Cauca Valley have, in addition to weymeri and submarginatus, two Mendelian traits that could in concert give rise to very accurate mimics of $E$. $h$. regalis. Assuming, for the sake of the following argument (see below), independent assortment (analysis of 11 families indicates no linkage between the mimetically relevant loci mentioned here except between $L^{G} / L^{C}$ and $\mathrm{Wo}_{1} / \mathrm{Wo}_{2}$, but the evidence is very weak; Linares, 1996), linkage equilibrium and Hardy-Weinberg distribution of genotype ratios (Table 2), the frequency of a specimen that is homozygous for all four traits conferring mimicry with $E . h$. regalis $\left(L^{C} L^{C} S_{2} S_{2} b_{2} W_{2} W_{2} Y_{2} Y l_{2}\right)$ is estimated to be nearly 1 in 100000 . Although no such specimen has been observed in the wild, two of Fassl's 89 specimens collected in 1908 are substantially better mimics of $E$. h. regalis (one of putative genotype $L^{C} L^{C} S b_{2} S b_{2} W_{1} W_{1} Y_{1} Y l_{2}$, shown in Fig. 4, and the other $\left.L^{C} L^{C} S_{2} S_{2} W_{2} W_{1} W_{2} Y_{1} Y l_{2}\right)$ than any occurring in collections taken between 1984 and 1991.

If these four traits reflect the genetic remnants of a past mimetic form, it should be possible to reconstitute experimentally a near-perfect mimic of $E . h$. regalis from individuals that occur presently in the Cauca Valley. This was achieved on two separate occasions. First, in 1988, from a weymeri female caught at Río Aguacatal, four $F_{1}$ offspring were produced - two gustavi and two weymeri - the latter with slight (heterozygous) expression of submarginatus. A cross between the two $\mathrm{F}_{1}$ weymeri (putative genotypes $L^{C} L^{C} S b_{l} S_{2} W_{2} W_{2} Y_{l} Y_{2}$ and $L^{C} L^{C} S_{1} S_{2} W_{2} o_{2} W_{2} Y_{2} Y_{2}$ for the male and female, respectively) gave rise to a phenotype indistinguishable from one of the (homozygous) type-specimens (Fig. 4) of $H$. w. submarginatus. [Staudinger (1896) described Heliconius weymeri, which was subsequently placed as a subspecies of $H$. cydno by Riffarth (1901), then Fassl (1912) described $H$. weymeri submarginatus, either unaware or ignoring previous taxonomic changes; in a taxonomic review of the genus Heliconius, Ackery \& Smiles (1976) placed $H$. w. submarginatus Fassl as a form of $H$. cydno weymeri; Fassl, 1912.] In the same group of sibs, the two additional minor traits (listed as 1 and 2 above) also appeared in homozygous condition, such that five out of the 43 members of the brood had a wing colour pattern nearly identical (putative genotype $\mathrm{L}^{C} \mathrm{~L}^{C} \mathrm{Sb}_{2} \mathrm{Sb}_{2} \mathrm{Wo}_{2} \mathrm{Wo}_{2} \mathrm{Yl}_{2} \mathrm{Yl}_{2}$, indistinguishable from the individual shown in Fig. 3; see also the individual shown at the bottom of Fig. 4) to that of E. h. regalis (compare Fig. 1 and Fig. 3). This laboratory-produced mimic bred true. Furthermore, among seven broods whose parents descended through six generations from the mentioned wild-caught female, 111 individuals (out of a total of 315 adding the members of all seven broods together) were homozygous for the four traits that control resemblance with $E . h$. regalis. That is to say, within the seven mentioned broods, 111 (indistinguishable from the individual shown in Fig. 3) near-perfect mimics of $E$. $h$. regalis were produced. Identical mimetic phenotypes were obtained in a second breeding experiment involving another wild-caught (September 1991) female of weymeri phenotype (putative geno- 
type $L^{C} L^{C} S b_{1} S b_{2} W_{2} W_{2} Y_{1} Y l_{2}$ ). This individual produced $17 \mathrm{~F}_{1}$ descendants, of which two were homozygous for all loci controlling resemblance to $E$. h. regalis, except 'yellow line' (putative genotype $L^{C} L^{C} \mathrm{Sb}_{2} \mathrm{Sb}_{2} \mathrm{Wo}_{2} \mathrm{Wo}_{2} \mathrm{Yl}_{1} \mathrm{Yl}_{2}$ ).

Other lines of evidence are consistent with the hypothesis that the adaptive peaks for wing pattern have changed recently in this system. First, the intensity of selection required to achieve the overall change (less than 1 per cent per locus over 80 years $=320$ generations) is well within the range reported acting on colour patterns of Heliconius in the field (Table 2; Mallet \& Barton, 1989). Secondly, loci controlling pattern elements not involved in mimetic resemblance have not changed in allele frequencies through time. Thus, the estimated frequencies of the allele $G_{2}$ (Linares, 1996), which controls the presence of the red-brown dot at the base of the costal forewing vein (Fig. 5), are not heterogeneous between 1908 and 1984-91 $(2 \times 2$ contingency table analysis, d.f. $=1, P=0.4714$; Table 2).

Four genetically controlled traits of the forewing colour pattern make some reared specimens of Heliconius cydno near-perfect mimics of the ithomiine butterfly, Elzunia humboldt regalis, a species that has declined in the face of habitat disturbance by humans. Most of these traits are now rare and have declined in frequency in the past 80 years. The most plausible explanation is that these alleles $\left(L^{C}, S b_{2}\right.$, $W_{2}$ and $Y l_{2}$ ) used to be part of a coadapted mimetic gene complex that conferred a very accurate phenotypic resemblance to $E$. $h$. regalis, and that this extinct mimetic 'race' (whose putative phenotype should have been nearly identical to that of the individual shown in Fig. 3) has been reconstituted by artificially bringing together, in the same individual, alleles that are now rare. This should not be taken to imply that natural selection associated with mimicry has been the only evolutionary factor responsible for bringing about the described changes in allele frequencies but simply that the evidence presented here indicates that natural selection associated with mimicry has played an important role in causing the mentioned changes in abundance of alleles responsible for generating wing pattern resemblance with respect to the co-mimics of $H$. cydno.

The rapid evolutionary change observed in Colombia's Cauca Valley $H$. cydno population is a striking example of a possible response to a change in Wright's metaphorical adaptive landscape. Because adaptive peaks can be directly observed in mimicry systems as co-mimic or model phenotypes, it is possible to connect ecosystem level changes (loss of forest) with specific changes in the adaptive landscape of a species (loss of $E$. $h$. regalis and the adaptive peak it defines). Humans, like the visual predators that act as agents of natural selection, are able to perceive directly the targets, as well as the results, of selection in mimetic systems. Although it is likely that other species are surviving major habitat disruptions with rapid but unperceived genetic changes, the vast majority disappear with the rain forest, finding no adaptive peaks to climb in the world that follows.

\section{Acknowledgements}

I thank J. Ayala, A. Barreto, S. Bramblett, K. Brown, E. Constantino, L. C. García, V. Jamri, L. P. Moreno, E. W. Schmidt-Mumm, M. Singer, C. D. Thomas and $\mathrm{R}$. Torres for helping me in various ways. Very special thanks are due to L. E. Gilbert for teaching me so much. I also thank the Instituto Vallecaucano de Investigaciones Científicas INCIVA in Cali, Fundación Segunda Expedición Botánica in Santafé de Bogotá, Smurfit Carton de Colombia, F. Arango and L. E. Gilbert for logistic support. The research was funded by National Science Foundation grants INT-8610430 and INT-8918819 and by Fondo Colombiano de Investigaciones Científicas y Proyectos Especiales Francisco José de Caldas COLCIENCIAS (Colombia) grants CO-6220-0500387 and CO-6220-05-008-89. Culture facilities were made possible by NSF DEB 790633 to L. E. Gilbert, University of Texas, Austin, U.S.A. My institutional affiliations during the period this research was carried out were: $1983-89$ as graduate student at University of Texas at Austin, U.S.A.; as a research associate at Fundación Segunda Expedición Botánica (Colombia) in 1987 and 1990-92; as junior faculty at Universidad Javeriana (Colombia) 1991-94; as Director of the Genetics Institute at Universidad de los Andes since November 1994.

\section{References}

ACKERY, P. R. AND SMILES, R. L. 1976. An illustrated list of the type-specimens of the Heliconiinae (Lepidoptera: Nymphalidae) in the British Museum (Natural History). Bull. Br. Mus. Nat. Hist. B, 32, 174-214.

Anon. 1981. Cali Santiago de Cali 450 Años de Historia. Alcaldía de Cali, Cali.

BRower, A. V. z. 1994a. Phylogeny of Heliconius butterflies inferred from mitochondrial DNA sequences (Lepidoptera: Nymphalidae). Mol. Phylogenet. Evol., 3, 159-174. 
BROWER, A. V. Z. 1994b. Rapid morphological radiation and convergence among races of the butterfly Heliconius erato inferred from patterns of mitochondrial DNA evolution. Proc. Natl. Acad. Sci. U.S.A., 91, 6491-6495.

BROWER, L. P., BROWER, J. V. Z. AND COLLINS, C. T. 1963. Experimental studies of mimicry. 7. Relative palatability and Müllerian mimicry among Neotropical butterflies of the subfamily Heliconiinae. Zoologica, 48, 65-84.

BRown, K. S. 1979. Ecologia geográfica e evolução nas florestas neotropicais. Livre-docencia thesis. Universidade Estadual de Campinas, Brazil.

BROWN, K. S. 1981. The biology of Heliconius and related genera. Ann. Rev. Ent., 26, 427-456.

BROWN, K. S. AND BENSON, w. w. 1977. Evolution in modern Amazonian non-forest islands: Heliconius hermathena. Biotropica, 9, 95-117.

CHAl, P. 1986. Field observations and feeding experiments on the responses of rufous-tailed jacamars (Galbula ruficauda) to free-flying butterflies in a tropical rain forest. Biol. J. Linn. Soc., 29, 161-189.

ELTRINGHAM, J. A. 1916. On specific and mimetic relationships in the genus Heliconius L. Trans. Ent. Soc. Lond., 1916, 101-155.

ENDLER, J. A. 1986. Natural Selection in the Wild. Princeton University Press, Princeton. NJ.

FASSL, A. H. 1912. Neue Heliconiusformen aus Kolumbien. Ent. Rdsch., 29, 55-56.

FASSL, A. H. 1914. Tropische Reisen. Das obere Caucatal und die Westcordillere. Ent. Rdsch., 31, 35-58.

FEDER, J. L., CHILCOTE, C. A. AND BUSH, G. L. 1988. Genetic differentiation between sympatric host races of the apple maggot fly Rhagoletis pomonella. Nature, 336, 61-64.

GILBERT, L. E. 1991. Biodiversity of a Central American Heliconius community: pattern, process, and problems. In: Price, P. W., Lewinsohn, T. M., Fernandes, T. W. and Benson, W. W. (eds) Plant-Animal Interactions: Evolutionary Ecology in Tropical and Temperate Regions, pp. 403-427. John Wiley \& Sons, New York.

GoULD, F. 1979. Rapid host range evolution in a population of the phytophagous mite, Tetranychus urticae. Evolution, 33, 791-802.

KeTtlewell, H. B. D. 1973. The Evolution of Melanism. Clarendon Press, Oxford.

LEES, D. R. 1981. Industrial melanism: genetic adaptation of animals to air pollution. In: Bishop, J. A. and Cook, L. M. (eds) Genetic Consequences of Man-made Change, pp. 129-176. Academic Press, London.

LEWONTIN, R. C. AND FELSENSTEIN, J. 1965. The robustness of homogeneity tests in $2 \times N$ tables. Biometrics, 21, 19-33.

LiNARES, M. 1989. Adaptive Microevolution through Hybridisation and Biotic Destruction in the Neotropics. PhD Dissertation, University of Texas.

LINARES, M. 1996. The genetics of the mimetic coloration in the butterfly Heliconius cydno weymeri. J. Hered., 87, $142-149$.

MAllet, J. 1984. Population Structure and Evolution of
Heliconius Butterflies. PhD Dissertation, University of Texas.

MALLET, J. 1986. Hybrid zones of Heliconius butterflies in Panama and the stability and movement of warning colour clines. Heredity, 56, 191-202.

MALLET, J. 1989. The genetics of warning colour in Peruvian hybrid zones of Heliconius erato and $H$. melpomene. Proc. R. Soc., 236, 163-185.

MALLET, J. 1993. Speciation, raciation, and colour pattern evolution in Heliconius butterflies: evidence from hybrid zones. In: Harrison, R. G. (ed.) Hybrid Zones and the Evolutionary Process, pp. 226-260. Oxford University Press, New York.

MALLET, J. AND BARTON, N. 1989. Strong natural selection in a warning colour hybrid zone. Evolution, 4, 421-431.

ramos, N. 1971. Cali Ciudad Conquistadora. Biblioteca de la Universidad del Valle, Cali.

RIFFARTH, H. 1901. Die Gattung Heliconius. Berlinger Entomol. Zeit., 46, 25-183.

SHEPPARD, P. M., TURNER, J. R. G., BROWN, K. S., BENSON, W. W. AND SINGER, M. C. 1985. Genetics and the evolution of Muellerian mimicry in Heliconius butterflies. Phil. Trans. R. Soc. B, 308, 433-613.

SINGER, M. C., THOMAS, C. D. AND PARMESAN, C. 1993. Rapid human-induced evolution of insect-host associations. Nature, 366, 681-683.

StAUDinger, O. 1896. Neue Heliconius-Arten und Formen. Dt. Ent. Z. Iris, 9, 284-317.

TABASHNIK, B. E. 1983. Host range evolution: the shift from native legume host to alfalfa by the butterfly, Colias philodice eriphyle. Evolution, 37, 150-162.

THOMAS, C. D., NG, D., SINGER, M. C., MALLET, J. L. B., PARMESAN, C. AND BILLINGTON, H. L. 1987. Incorporation of a European weed into the diet of a North American herbivore. Evolution, 41, 892-901.

TORRES, R. AND TAKAHASHI, M. 1983. Lista de la subfamilia Heliconiinae (Lepidóptera, Nymphalidae) colectados en el Valle del Cauca y su vecindad, Colombia, América del Sur. Tyô to $G a, 33,103-131$.

TURNER, J. R. G. 1971a. Two thousand generations of hybridization in a Heliconius butterfly. Evolution, 25, 471-482.

TURNER, J. R. G. 1971b. The genetics of some polymorphic forms of the butterflies Heliconius melpomene (Linnaeus) and $H$. erato (Linnaeus). II. The hybridization of subspecies of $H$. melpomene from Surinam and Trinidad. Zoologica, 56, 125-157.

TURNER, J. R. G. 1974. Breeding Heliconius in a temperate climate. J. Lepidopt. Soc., 28, 26-33.

TURNER, J. R. G. 1981. Adaptation and evolution in Heliconius: a defense of NeoDarwinism. Ann. Rev. Ecol. Syst., 12, 99-121.

TURNER, J. R. G. 1987. The evolutionary dynamics of Batesian and Muellerian mimicry similarities and differences. Ecol. Entomol., 12, 81-95.

TURNER, J. R. G. 1988. The evolution of mimicry: a solution to the problem of punctuated equilibrium. $A m$. Nat., 131 (Suppl.), S42-S66. 